\title{
LXVII. Note on the diffusion of neon through hot quartz
}

\section{O.W. Richardson \& R.C. Ditto}

To cite this article: O.W. Richardson \& R.C. Ditto (1911) LXVII. Note on the diffusion of neon through hot quartz, Philosophical Magazine Series 6, 22:131, 704-706, DOI: 10.1080/14786441108637167

To link to this article: http://dx.doi.org/10.1080/14786441108637167

册 Published online: 20 Apr 2009.

Submit your article to this journal $\sqsubset \pi$

Џ Article views: 3

Q View related articles $\square$

Citing articles: 1 View citing articles 5 


\section{[ 704 ]}

LXVII. Note on the Diffusion of Neon through Hot Quartz. $B y$ O. W. Richandson, Professor of Physics, and R. C. Dinto, Fellow in Physics, Princeton University *

$\mathrm{T}$ the course of some experiments which were undertaken 1 to try to detect the presence of the heavier inert gases (xenon, krypton, argon, and neon) in minerals, we have observed that nean diffuses through red-hot quartz tubes. The possession of a similar property by helium has been known for some time, and appears to have been observed first by A. Jacquerod and F. L. Perrot $†$.

The method originally adopted consisted in heating the mineral in a closed silica-ware tube, initiallv exhausted. After the heating, the gas evolved was drawn off into a large exhausted reservoir. It was subsequently compressed into another heated quartz tube containing metallic calcium. Both the calcium and the mineral were heated to a temperature of about $1000^{\circ} \mathrm{C}$. After exposure to the hot calcium, the gas was forced into a narrow capillary tube, where its spectrum could be examined by means of a Hilger wave-length spectroscope. Our experience is that hot calcium absorbs all the chemically active gases completely except hydrogen. We tried different temperatures between $800^{\circ} \mathrm{C}$. and $1200^{\circ} \mathrm{C}$., but always found that the calcium hydrogen compound exerted a dissociation pressure which, though minute, was large enough to be troublesome. We could not use higher temperatures on account of the silica-ware tabes becoming soft and collapsing under the atmospheric pressure. The hydrogen contamination was got rid of by forcing the gas into a small tube provided with a platinum tube heated by an electric current. The hydrogen diffused out through the hot platinum and burnt in the air of the room. These processes were gone through until we got a good clean spectrum showing the mercury lines and the lines of the inert gases present. As a rule the primary hydrogen lines were also visible, but not always.

The presence of neon in our apparatus was first noticed when a specimen of witherite from Northumberland, England, had been heated for a long time. We subsequently succeeded in proving that this mineral did not give off neon, and then tried the experiment with a new silica-ware tube which did not contain, and never had contained any foreign substance. After the exhausted tube had been heated for about one hour the gas was drawn off and examined. It was found to give

- Communicated by the Authors.

$\dagger$ Comptes Rendus, cxxxix. p. 789 (1904). 
a faint "blue argon" spectrum with the yellow helium line. After about three hour's' heating the helium spectrum was fully developed, and the strong neon line at 5852 was well marked. The tuke was then left hot all night. Next morning the helium and neon spectra were both quite strong, all the prominent neon lines being easily recognized. We could not be certain of any increase in the intensity of the blue argon spectrum which was present, either in this or in other similar experiments. This is important since it proves that the helium and neon had not leaked into the apparatus through the sealing-wax joints which connected to the two quartz tubes. In that case the argon spectrum should have increased proportionately with the others. This possibility is also exciuded by the fact that the helium and neon present in the air cannot be detected spectroscopieally in presence of the very large excess of argon which accompanies them. We have tested this question several times very carefully by examining the spectrum of the inert gases of the atmosphere under conditions similar to those which prevailed during the other experiments. We were never able to detect even the strongest helium and neon lines. The faint argon spectrum which was observed arose in all probability from the trace of air absorbed by the walls of the tubes before the heating commenced.

It is clear from these experiments that neon diffuses through quartz at about $1000^{\circ} \mathrm{C}$., but its coefficient of diffusion is smaller than that of helium. This follows since the helium is visible first, although there is about ten times as much neon as helium present in the atmosphere. Of course helium is more sensitive to the spectroscopic test than neon, but it does not seem likely that this will account for the facts, as the strong neon line appears at about the same time as the weak helium lines, in spite of the disparity in the amounts of the two gases present in the atmosphere. Arguing from the general similarity in the properties of the inert gases, it would seem likely that argon also would diffuse through hot quartz. If it does, the coefficient of diffusion must be very small, otherwise accumulation of argon would certainly have been observed in these experiments. This question is by no means easy to test experimentally, as there is al ways the possibility that a minute accumulation of this gas might arise from defective airtightness of the apparatus.

It seems likely that an easy method of measuring the amount of helium and neon in the atmosphere might be based on this property of diffusion through heated quartz. By attaching a quartz tube heated to a constant temperature to 
a large reservoir, and observing the quantity of inert gas which had accumulated after a series of suitable intervals of time, it would in all probability be possible to deduce from an examination of the results, not only the final equilibrinm amount of helium and neon together, but also the quantities of the two individually, as well as their coefficients of diffusion.

Palmer Physical Laboratory, Princeton, N.J.

LXVIII. The Induction-Coil. By E. Taylor Jones, D.Sc., Professor of Physics in the University College of North Wales, Bangor, and D. E. RoBents, B.Sc., Fellow of the University of Wales*.

[Plates XII. \& XIII.]

THE experiments described in the present paper were 1 made with the object of determining the elements (periods, amplitudes, damping-factors, and phases) of the two electrical oscillations which are set up in the secondary of an induction-coil when the primary current is interrupted, and of calculating hence the maximum value of the secondary potential and the potential at any time during the oscillations.

The principal difficulties connected with the calculation of the secondary potential of an induction-coil are (1) the determination of the effective self- and mutual-inductances of the coils, (2) the determination of the capacity of the secondary coil ; the first owing to the want of proportionality between magnetic induction and magnetizing force in the iron core, the second owing to the smallness of the capacity and to the fact that the capacity is distributed along the coil. Some attempt was made in the experiments described below to overcome these difficulties, but there are other circumstances, including condenser losses, hysteresis, and irregularities in the working of the interrupter, which will have to be taken into account, or avoided, before a complete solution of the induction-coil problem can be reached.

The papers of Oberbeck + , Walter $\ddagger$, and Lord Rayleigh $\S$, on induction-coil potentials are well-known and are therefore only mentioned here.

* Communicated by the Authors:

† Oberbeck, Wied. Ann., lxii. p. 109 (1897); lxiv. p. 193 (1898).

\pm Walter, Wied. Ann., lxii. p. 300 (1897); lxvi. p. 623 (1898).

$\$$ Rayleigh, Płil. Matg., ii. p. 581 (1001). 